\title{
IDENTITAS BUDAYA BATAK TOBA DALAM STRUKTUR MISE EN SCENE PADA FILM LAMARAN
}

\author{
${ }^{1}$ Muhammad Ali Mursid Alfathoni \\ ${ }^{2}$ Dani Manesah \\ Prodi Televisi dan Film \\ Fakultas Seni dan Desain Universitas Potensi Utama \\ Mhd.ali8mursid@gmail.com ${ }^{1), m a n e s a h h @ g m a i l . c o m ~}{ }^{2)}$
}

\begin{abstract}
ABSTRAK
Tujuan penelitian ini adalah untuk mengungkapkan bentuk identitas budaya Batak Toba yang terdapat dalam sturuktur mise en scene pada film Lamaran. Struktur mise en scene merupakan merupakan segala sesuatu yang terlihat di depan kamera yang siap diambil gambarnya. Melalui struktur mise en scene tersebut akan didapat bentuk wujud dari identitas budaya Batak Toba yang ada pada film Lamaran. Film Lamaran merupakan sebuah film dengan genre drama komedi. Film Lamaran disutradarai oleh Monty Tiwa yang diproduksi pada tahun 2015. Penelitian ini menggunakan metode pendekatan secara kualitatif dengan teknik mendeskripsikan objek penelitian dan semua data yang digunakan dalam penelitian ini. Hasil penelitian ini menunjukkan bahwa identitas budaya Batak Toba terdapat pada tiga unsur yang ada dalam struktur mise en scene. Unsur tersebut adalah setting dengan latar motif ukiran gorga, kostum dan tata rias tokoh yang mengenakan kain ulos dengan tata rias yang natural, dan pemain dan pergerakan yang mencerminkan sistem kekerabatan masyarakat Batak Toba.
\end{abstract}

Kata kunci: batak toba, film lamaran, identitas, mise en scene.

\section{ABSTRACT}

The purpose of this research is to reveal the form of Toba Batak cultural identity contained in the structure of the mise en scene in the film Lamaran. The structure of the mise en scene is everything that is visible in front of the camera that is ready to be photographed. Through the structure of the mise en scene, we will get the form of Toba Batak cultural identity in the film Lamaran. Film Application is a film with a comedy drama genre. Film Application directed by Monty Tiwa which was produced in 2015. This study uses a qualitative approach method with the technique of describing the object of research and all data used in this study. The results of this study indicate that the Toba Batak cultural identity is contained in three elements in the structure of the mise en scene. These elements are a setting with a background of gorga carving motifs, costumes and make-up of figures wearing ulos cloth with natural make-up, and players and movements that reflect the kinship system of the Toba Batak community.

Keywords: batak toba, film lamaran, identity, mise en scene.

\section{PENDAhULUAN}

Film yang diangkat dari kearifan lokal yang ada disuatu masyarakat tentu membawa dampak yang sangat positif terhadap kelestarian identitas budaya lokal suatu daerah. Dengan adanya film yang diangkat dari tema identitas budaya lokal, tentu masyarakat luas akan lebih mengenal kekayaan budaya yang dimiliki oleh bangsa Indonesia. Film hadir sebagi media yang mampu mempresentasikan konsep audio visual yang mampu menjadi media tontonan yang menghibur dalam kehidupan manusia. Selain menghibur,film juga mampu menanamkan berbagai nilai dan cara pandang terhadap segala sesuatu (Arsi \& Sobur, 2019) Sebagai media audio visual, konsep yang dikontruksikan ke 
dalam film mampu menampilkan realita kenyataan yang dapat menunjukkan sebuah identitas. Hal demikian, bertujuan agar film yang diproduksi dapat diterima oleh masyarakat yang memiliki kebudayaan tersebut. Menurut Amura (1989: 91) bahwa film memiliki arti melihat sesuatu yang hidup atau seolah-olah hidup. Oleh karena itu, film yang dikontruksikan dari kearifan lokal kebudayaan harus dapat membawa penonton untuk melihat dan merasakan bahwa film yang ditonton merupakan realita yang sebenarnya.

Kekayaan budaya yang dimiliki oleh bangsa Indonesia merupakan bentuk keunggulan yang dimiliki oleh bangsa Indonesia. Adanya aneka ragam kebudayaan tersebut menjadi potensi yang besar bagi insan perfilman Indonesia untuk dijadikan karya film. Adanya suatu budaya diangkat ke media film tentu sangat membantu dalam menjaga kelestarian budaya tersebut. Pada saat sekarang ini, film bukan hanya sebagai media seni yang dapat menghibur, akan tetapi, juga dijadikan sebagai praktek sosial kebudayaan. Hal tersebut ditandai dengan kemampuan film dalam mempengaruhi kehidupan sosial kebudayaan disuatu kelompok maupun individu di suatu masyarakat. Film menjadi praktek sosial yang mempengaruhi kehidupan sehari-hari melalui fandom, gosip, fashion, dan seluruh aktifitas yang terkait dengan pembentukan identitas kebudayaan (Thalib, 2017). Wujud identitas budaya Batak Toba yang tercermin dalam struktur mise en scene pada film Lamaran terdiri sistem nilai, norma, kepercayaan dan sistem kekerabatan maupun tindakan.Batak Toba merupakan etnis suku Batak yang ada di Sumatera Utara. Etnis Batak Toba berasal dari wilayah Toba Samosir. Seiring berjalannya waktu etnis suku Batak Toba menyebar luar ke berbagai wilayah di Indonesia.

Film Lamaran merupakan sebuah film karya sutradara Monty Tiwa yang rilis pada 15 Juli 2015. Film Lamaran diproduksi oleh Rapi Films dengan durasi 1 jam 35 menit 56 detik. Film Lamaran menceritakan seorang Tiar Sarigar seorang pengacara muda berdarah Batak yang sangat ambisius dalam menyelesaikan masalah hukum maupun masalah asmara. Film sebagai sebuah media yang menghadirkan presentasi visual, tentu tidak lepas dari struktur mise en scene yang terdiri dari setting, kostum dan tata rias, pencahayaan, dan pergerakan pemain. Menurut Pratista (2008) bahwa mise en scene merupakan sesuatu yang terlihat di depan kamera. Salah satu unsur pendukung identitas budaya dalam film digambarkan melalui aspek mise en scene. Film akan menjadi sebuah karya audio visual yang bagus dan menarik jika sutradaranya senantiasa memperhatikan aspek mise en scene nya. Aspek mise en scene dalam sebuah film memiliki peran yang sangat penting, terlebih film yang menampilkan identitas budaya lokal daerah seperti hanya film Lamaran. Konsep mise en scene yang dituangkan sutradara dalam sebuah film tidaklah jauh berbeda. Akan tetapi, yang menjadi perbedaanya adalah tampilan visual, sasaran genre dari konsep mise en scene yang dihasilkan.

Akan tetapi, unsur mise en scene yang terdapat dalam sebuah film tentu tidak dapat berdiri sendiri, namun unsur mise en scene memiliki hubungan keterkaitan yang sangat erat dengan unsur sinematik seperti sinematografi, suara, dan editing. Dengan adanya paduan berbagai unsur dalam penciptaan film, tentu film yang diproduksi memiliki kualitas visual yang menarik seperti halnya film Lamaran. Identitas budaya Batak Toba yang tergambarkan dalam struktur mise en scene pada film Lamaran tentu memiliki informasi, nili-nilai, maupun makna yang sangat berguna bagi penonton. Dalam konteks kebudayaan Indonesia, bahwa nilai-nilai budaya yang ada serta tumbuh di tengah-tengah masyarakat tentu memiliki arti serta keunikan tersendiri yang bisa terlihat dari berbagai sudut pandang. Struktur mise en scene yang mencerminkan identitas budaya Batak Toba dalam film Lamaran menjadi suatu keunikan untuk dikaji lebih dalam. Keunikan tersebut dapat terlihat dari unsur mise en scene yang mencerminkan konteks identitas budaya Batak yang mulai terkikis seiring perkembangan zaman. Penggarapan konsep unsur mise en scene dalam film Lamaran untuk mencerminkan identitas budaya Batak Toba dikemas seolah-olah 
memang terjadi dalam realita tataran masyarakat tersebut. Proses penggarapan unsur mise en scene dalam film Lamaran mencangkup aspek setting, kostum dan tata rias, akting. Selain itu, dalam film Lamaran juga menerapkan dialek kas etnik Batak Toba.

Berdasarkan penjabaran diatas, penulis tertarik untuk melakukan penelitian lebih lanjut tentang identitas budaya Batak Toba yang terdapat pada film Lamaran berdasarkan deskripsi kualitatif terhadap penerapan struktur mise en scene. Melalui deskripsi yang dilakukan secara kualitatif terhadap penerapan struktur mise en scene, akan diketahui sejauh mana realita visual menyampaikan identitas budaya Batak Toba yang ada pada film Lamaran. Dengan demikian, struktur mise en scene yang menunjukkan identitas budaya Batak Toba yang terdapat pada film Lamaran dapat diungkapkan dengan sebaik mungkin.

\section{II.STUDI LITERATUR}

Hasil penelitian Amirah Anis Thalib yang terdapat dalam jurnal SATWATIKA: Kajian Ilmu Budaya dan Perubahan Sosial dengan judul "Isu-Isu Identitas Budaya Nasional dalam Film "Tenggelamnya Kapal Van der Wijck" tahun 2017. Hasil penelitian menunjukkan bahwa perbedaan suku dan kelas sosial tentu menjadi sebuah pertimbangan ketika ingin melangsungkan sebuah pernikahan. Amirah Anis Thalib menggunakan pendekatan multikulturalisme Will Kymlicka untuk menginterpretasi dan menemukan makna dibalik temuan data yang terdapat dalam film. Amirah Anis Thalib menemukan bahwa dalam film Tenggelemnya Kapal Van Der Wijck terdapat identitas suku dan kelas sosial yang dikomunikasikan ke dalam film tersebut. Penelitian yang dilakukan oleh Amirah Anis Thalib dan peneliti sama menggunakan film sebagai objek dalam penelitian. Amirah Anis Thalib lebih kearah tentang isu-isu sebuah identitas budaya nasional yang terdapat dalam film Tenggelamnya Kapal Van der Wijck. Akan tetapi, peneliti lebih kerah pencarian bentuk identitas budaya Batak Toba yang terdapat pada film Lamaran.

Penelitian yang menjadi rujukan peneliti selanjutnya adalah, penelitian Ranang Agung Sugihartono dan Dyah Ayu Wiwid Sintowoko, tahun 2014. Penelitian ini menunjukkan bahwa kostum merupakan bentuk ciri khas dari tokoh dan karakter yang terdapat pada film Soekarno. Kostum yang digunakan oleh para karakter tokoh pada film Soekarno mampu menunjukkan kekhasan dari setiap tokoh. Objek penelitian ini dengan penelitian penulis sama mengunakan film sebagai objek. Adapun yang menjadi pembedanya terletak pada interpretasi yang dilakukan. Peneliti lebih kearah melihat kostum yang mencerminkan identitas budaya Batak Toba yang terdapat dalam film Lamaran.

\section{PEMBAHASAN}

\section{III.1 Benturan Budaya Lokal Pada Film Lamaran}

Kekayaan budaya merupakan salah satu keunggulan yang dimiliki oleh bangsa Indonesia. Indonesia dengan beragam suku dan adat istiadat tentu memiliki potensi budaya yang sangat besar. Beraneka ragam budaya yang dimiliki bangsa Indonesia sudah semestinya dijaga kelestariannya. Salah satu bentuk pelestarian nilai budaya terlihat ketertarikan insan perfilman Indonesia mengangkat berbagai konteks budaya Indonesia ke karya seni audio visual yang lebih dikenal dengan film. Perkembangan industri perfilman Indonesia saat ini, tentu membutuhkan ide cerita yang unik dan memiliki daya tarik agar film yang sudah diproduksi dilirik oleh penonton. Dengan adanya suatu budaya yang diangkat ke media film tentu sangat membawa dampak yang positif terhadap perkembangan zaman terutama generasi muda. Perkembangan zaman dan arus informasi yang tidak dapat dibentung dan beraneka ragam budaya masuk Indonesia dari berbagai celah, tentu perlahan-lahan akan membuat budaya lokal Indoneia hilang dimakan masa. 
Dengan demikian, tentu akan membuat generasi muda lupa dan tidak mengenal budaya asli Indonesia secara umum. Oleh karena itu, dengan adanya film yang bernuansa budaya lokal Indonesia yang di tayang di bioskop, tentu sedikit banyaknya akan dapat membuka cakrawala berpikir generasi muda untuk sadar akan kekayaan budaya Indonesia. Dengan perkembangan zaman dan teknologi informasi saat ini, generasi muda lebih banyak memilih media informasi seperti film sebagai media audio visual untuk mengisi waktu luang dari pada harus duduk mendengarkan orang tua, nenek maupun kakek yang memiliki pengetahuan tentang budaya, adat istiadat, silsilah keluarga.

Salah satu bentuk tema budaya yang menjadi lirikan insan perfilman Indonesia untuk diangkat ke film adalah budaya Batak. Etnis Batak yang cukup dikenal di daerah Sumatera Utara tentu memiliki keunikan tersendiri dari segi budaya, sosial, adat istiadat, Bahasa, dan logat berbicara. Adanya keunikan tersebut tentu menjadi faktor " $X$ " yang membuat para sutradara untuk terus memasukkan unsur budaya Batak ke karya Film seperti halnya film Lamaran sutradara Monty Tiwa. Monty Tiwa mengemas unsur budaya Batak dalam Film Lamaran dengan unsur komedi, sehingga film Lamaran menjadi sebuah tonton yang ringan bagi setiap kalangan. Adanya unsur komedi dalam film tersebut, tentu informasi seputar identitas budaya Batak Toba yang tercermin dalam struktur mise en scene tentu akan menjadi sebuah tonton yang menghibur dan penuh informasi. Film Lamaran secara keseluruhan sangat memberikan informasi tentang identitas budaya Batak Toba. Identitas tersebut sangat terlihat jelas dari benturan budaya Batak dan Sunda yang disajikan oleh Monty Tiwa dalam media film.

Benturan budaya tersebut terlihat sangat jelas dari konflik yang terjadi antara $\mathrm{Bu}$ Sarigar dan Bu Euis. Bu Sarigar sebagai orang Batak sangat berpegang teguh terhadap prinsip budaya serta adat istiadat yang ia yakini, begitu juga sebaliknya Bu Euis sebagai orang Ibu berdarah Sunda juga sangat menjunjung tinggi nilai-nilai budaya serta adat istiadat yang diwarisinya. Benturan budaya terjadi antara Bu Sarigar dan Bu Euis menjadi konflik utama yang mengiringi kisah perjuangan Aan untuk mendapatkan marga agar bisa menikahi Tiar. Tiar sebagai seorang perempuan berdarah Batak tentu keluarga Tiar sangat berharap agar Tiar menikah dengan seorang lelaki yang berasal dari darah yang sama. Akan tetapi, Tiar lebih memilih Aan untuk menjadi suaminya agar Tiar bisa menyelesaikan misinya untuk memecahkan kasus korupsi yang menimpa pak Basuki. Sebagai seorang pengacara tentu pilihan Tiar dianggap tidak sesuai oleh keluarga Tiar karena Aan hanya seorang resepsionis dan tidak berdarah Batak. Akan tetapi, hal tersebut tidak membuat Tiar dan Aan mundur. Dengan bantuan La Abo dan Sasha, Aan berhasil mendapatkan marga sebagai salah satu syarat agar bisa menikahi Tiar.

\section{III.2 Identitas Budaya Batak Toba Dalam Perwujudan Mise En Scene Pada Film Lamaran}

Dalam sebuah produksi film, seorang sutradara memiliki peran dan tanggung jawab penuh terhadap kualitas produksi mulai dari tahapan pra produksi sampai selesai. Sutradara mengontrol terhadap aspek struktur maupun unsur pembentukan sebuah film seperti aspek pengadengan, pemain, gambar, bahkan aspek editing pada sebuah film. Untuk menghasilkan hasil produksi yang bagus tentu membutuhkan kerja tim yang penuh dengan solidaritas dan kreatifitas. Untuk itu, sebagai seorang sutradara harus bisa melihat dan mengukur potensi kerja kreatif maupun solidaritas tim yang direkrut dan disepakati dengan produser film. Oleh karen itu, tentu seorang sutradara membutuhkan strategi yang mumpuni agar mampu mewujudkan film yang sesuai dengan desain dan harapan yang sudah dirancang sebelum proses produksi berjalan. Film sebagai sebuah media yang mampu menyajikan sebuah kisah atau cerita dalam balutan struktur dramatik. Setiap adegan yang tercermin dalam struktur dramatik pada film Lamaran tentu tidak lepas dari 
perwujudan struktur mise en scene. Adapun bentuk penjabaran akan identitas budaya Batak Toba dalam struktur mise en scene pada film Lamaran seperti berikut :

\section{Setting}

Setting memiliki peran yang penting dalam film. Setting memiliki fungsi untuk memberikan informasi tentang lokasi maupun waktu dalam sebuah film. Adanya setting dalam sebuah film, memiliki kemampuan dalam memberi makna pada struktur naratif pada sebuah film. Adanya setting pada sebuah film sangat membantu sutradara dalam memberikan kontrol secara artistic Ketika sutradara menyutradarai sebuah film. Menurut Wiyanto (2002) setting merupakan latar cerita, penggambaran waktu, tempat, dan suasana terjadinya sebuah cerita. Film Lamaran secara keseluruhan mengambil lokasi syuting di daerah Jakarta. Akan tetapi, ada beberapa setting yang mencerminkan identitas budaya Batak Toba. Setting tersebut dijadikan sebagai properti pelengkap agar tema budaya Batak Toba pada Film Lamaran dapat terlihat dalam konteks visual film. Nurgiyantoro (2002) dalam Santosa (2011) menyatakan bahwa setting adalah dasar, mengarah pada pengertian tempat, hubungan waktu dan lingkungan sosial tempat terjadinya peristiwa-peristiwa yang diceritakan. Adapun setting yang menunjukkan identitas budaya Batak Toba pada Film Lamaran terlihat pada adegan yang terdapat gambar berikut :

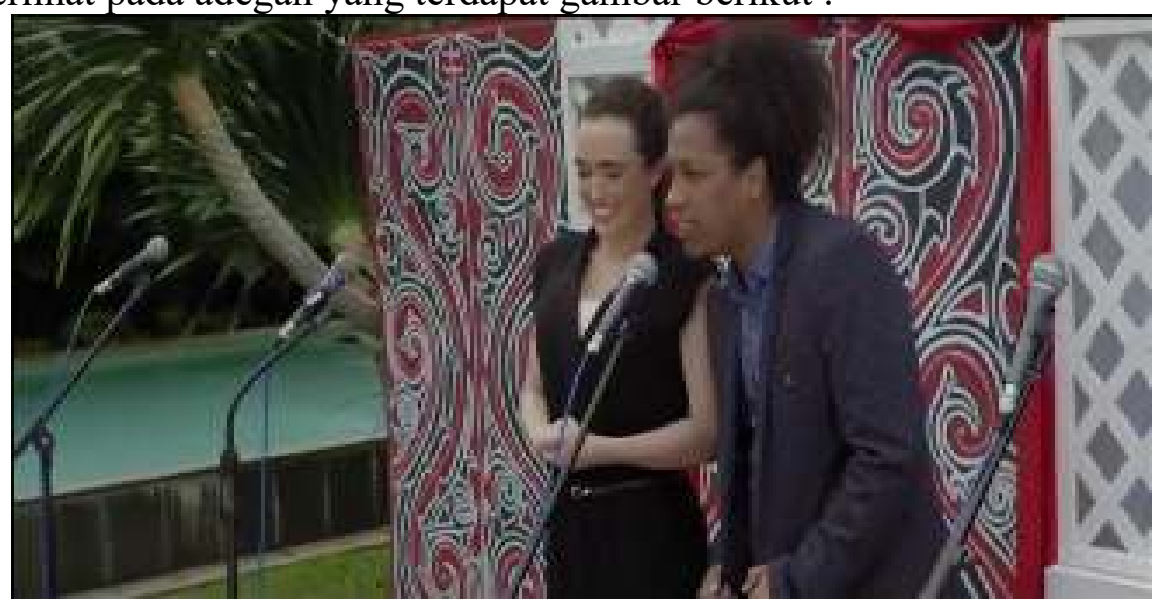

Gambar. 1 Setting Panggung Yang Mencerminkan

Identitas Budaya Batak Toba

(Sumber: Capture film Lamaran, 2020)

Pada adegan yang terlihat pada gambar diatas terdapat dua orang yang sedang berada di atas panggung dan berlatar belakang motif gorga Batak Toba. Menurut Austin Alexander Parhusip mengatakan bahwa gorga Batak Toba adalah kesenian ukir ataupun pahat yang biasanya terdapat pada bagian luar (eksterior) rumah adat Batak Toba dan alat kesenian (gendang, serunai, kecapi), dan lain sebagainya (wawancara, 04 Desember 2019). Sebagai ukiran dekoratif, gorga tradisional identik dengan rumah raja atau rumah orang kaya. Selain rumah adat Batak Toba, gorga tradisional juga terdapat pada perangkat uringuringan (alat musik), peralatan berburu, dan benda-benda kerajinan (Saragi, 2008). Komposisi gambar dan setting waktu pagi yang terdapat dalam scene tersebut menerapkan komposisi dinamis dimana objek dalam gambar tersebut berada ditengah, yang mampu menciptakan kesan riang. Adapun setting yang terdapat pada adegan diatas merupakan setting peristiwa. Setting peristiwa yang menggunakan motif gorga Batak Toba pada adegan gambar diatas mencerminkan hubungan perilaku kehidupan sosial budaya masyarakat Batak Toba. Cerminan perilaku kehidupan sosial tersebut tentu berkaitan erat dengan kebiasaan hidup, adat istiadat, tradisi, keyakinan, pola pikir, dan sebagainya. 
Adanya pemanfaatan setting peristiwa dengan motif gorga tentu sutradara ingin menunjukkan realita yang sebenarnya bahwa motif gorga merupakan sebuah identitas seni ukir yang dimiliki oleh etnis Batak Toba. Ketika zaman kemerdekaan, masyarakat Batak Toba memperlakukan motif-motif gorga sebagai identitas 'kearifan lokal'(Andriyanti, 2008). Selain itu, setting waktu dan peristiwa yang terdapat pada adegan gambar diatas juga mencerminkan sistem kepercayaan. Hal tersebut ditegaskan oleh Santosa (2006) bahwa masyarakat tradisional berkomunikasi dengan membangun kekuatan mental dan spiritual, agar mereka dapat memberikan semangat hidup bagi warganya dalam mencapai cita-cita dan harapan.

\section{Kostum dan Tata Rias}

Kostum dan tata rias dalam film merupakan elemen yang tidak bisa dipisahkan dalam struktur mise en scene. Kostum dan tata rias dalam film merupakan elemen untuk mendukung artistik. Kostum dan tata rias memiliki fungsi sebagai alat untuk bercerita dalam melakukan komunikasi dalam visual film secara detail dari kepribadian masingmasing karakter yang diperankan dalam layar film. Hal tersebut dipertegas oleh Mcdonald (2010) yang berbunyi, With costume holding this much potential to support or undermine the characterization and narrative of the film, it seems important to consider some of these theories before moving on to discuss what the radical on-screen changing of costume can. Sebagai salah satu unsur yang terdapat dalam struktur mise en scene. Kostum dalam sebuah film tentu dapat dilihat, diimajinasikan, dirasakan, dan dihayati oleh penonton sebagai bentuk motivasi (Sugihartoni \& Sintowoko, 2018). Oleh karena itu, melalui kostum yang digunakan oleh pemain film Lamaran tentu dapat mencerminkan karakter tokoh, latar belakang budaya yang diangkat, serta identitas sosial budaya yang diperankan oleh tokoh pada film tersebut. Melalui kostum tentu juga dapat membuat sudut pandang melalui aksesoris pelengkap yang dikenakan oleh seorang tokoh pada film Lamaran. Pada film Lamaran Kostum yang mencerminkan identitas budaya Batak Toba terlihat dari jenis ulos serta pakaian adat yang digunakan dalam adegan pernikahan Aan dan Tiar. Ulos merupakan jenis kain adat tradisional yang sering digunakan untuk upacara adat pada suku Batak seperti halnya Batak Toba. Kain ini merupakan salah satu syarat utama dalam melakasanakan upacara adat Batak Toba. Keberadaan kain Ulos dalam suatu upacara juga dapat menjadi identitas yang jelas bagi etnis Batak Toba. Penggunaan ulos juga merupakan bagian dari cara penghormatan kepada orang-orang yang melaksanakan adat maupun kepada para undangan yang menghadiri acara adat tersebut.

Menurut Austin Alexander Parhusip, setiap ulos mempunyai motif atau biasa disebut dengan gorga, pada dasarnya ulos mempunya tiga induk ulos, diantaranya ulos mangiring, ulos maratut dan ulos suri-suri ganjang dan ketiganya disebut juga dengan ulos gomgom dari ketiganya kemudian berkembang menjadi beraneka bentuk dan ragam (wawancara, 04 Desember 2019). Adapun adegan tokoh yang memakai kostum ulos seperti terlihat pada adegan gambar dibawah ini. 


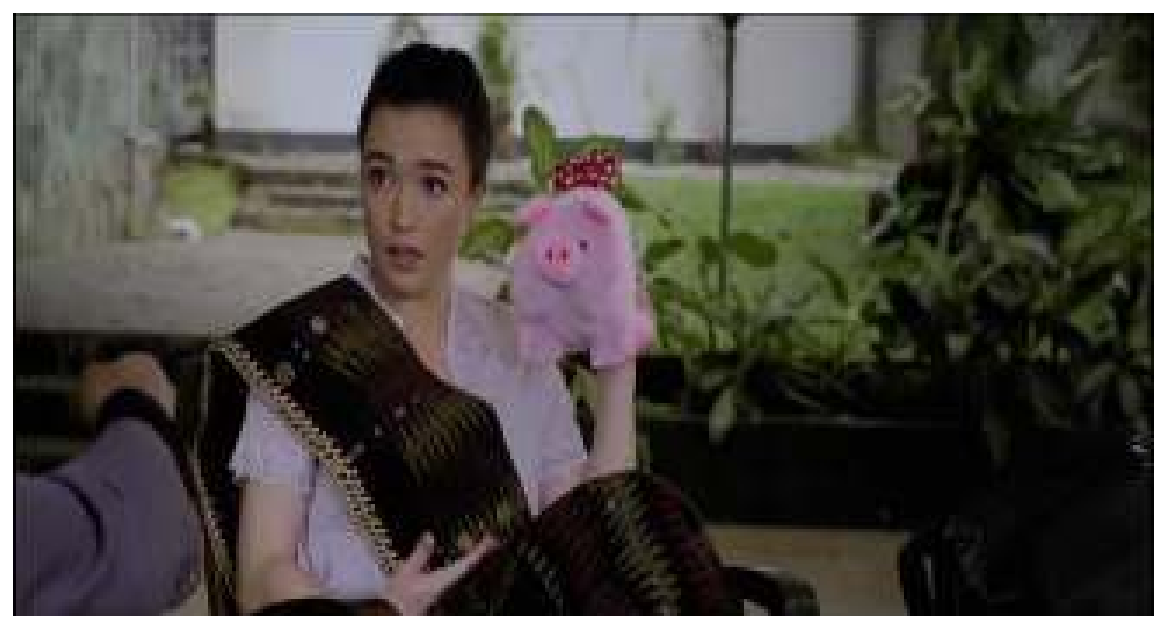

Gambar. 2 Sasha Memakai Ulos

(Sumber: Capture film Lamaran, 2020)

Pada adegan yang terlihat pada gambar diatas, terlihat Sasha sedang mengenakan sebuah ulos. Jenis ulos yang digunakan oleh Sasha merupakan jenis ulos suri ganjang. Jenis ulos tersebut bermotif seperti bentuk sisir memanjang, ulos ini merupakan ulos yang diwariskan turun menurun kepada anak cucu dalam keluarga. Ulos ini memiliki 33 garis. motif dalam ulos ini memliki arti bahwa ciri khas orang Batak yang teguh dalam satu pendirian dan selalu menurun kepada anaknya. Adegan yang terdapat pada gambar diatas diambil dengan menggunakan teknik medium shot. Teknik medium shot merupakan teknik yang digunakan untuk pengambilan gambar yang dimulai dari pinggang hingga ke kepala. Medium shot merupakan sebuah ukuran shot yang memiliki motivasi untuk melihat gesture tubuh dari si objek (Pratista, 2008). Efek dari penggunaan teknik medium shot ini juga akan menampilkan bagian atas kepala hingga ke pinggang, sehingga pada shot ini yang menjadi fokus adalah pergerakan dari badan bagian atas objek seperti tangan dan akan menampilkan visualisasi gambar yang apik. Selain itu, adegan yang terlihat pada gambar diatas juga ditambah dengan penggunaan komposisi gambar Sasha yang sedang memegang sebuah boneka Babi. Komposisi tersebut mampu smenampilkan ekspresi subjek yang pas. Dalam adegan yang terlihat pada gambar diatas komposisi yang digunakan adalah komposisi dinamis. Komposisi dinamis sendiri merupakan peletakkan subyek yang cenderung lebih berat ke sebelah (atas, bawah, kiri, atau kanan). Selain itu, Tata rias yang digunakan Sasha terlihat lebih natural. Penggunaan tata rias yang natural dan terlihat alami tentu bertujuan untuk mencerminkan karakter yang diperankan oleh Sasha yang bersahaja dalam balutan kain ulos.

Selanjutnya, penggunaan kostum ulos juga terlihat pada adegan seorang kakek yang sedang mengangkat sebuah kursi berwarna hijau dengan menggunakan sebuah ulos. Ulos tersebut bernama ulos ragi idup, memiliki arti yaitu ulos yang tertinggi derajatnya. Ulos ini terdiri atas tiga bagian, yaitu dua sisi yang ditenun sekaligus, dan satu bahagian tengah yang ditenun tersendiri dengan sangat rumit. Bagian tengahnya terdiri ata tiga unsur, yaitu bagian tengah atau badan, dan dua bahagian lainnya sebagai ujung tempat pigura lelaki (pinarhalak hana) dan ujung tempat pigura perempuan (pinarhalak boruboru). 


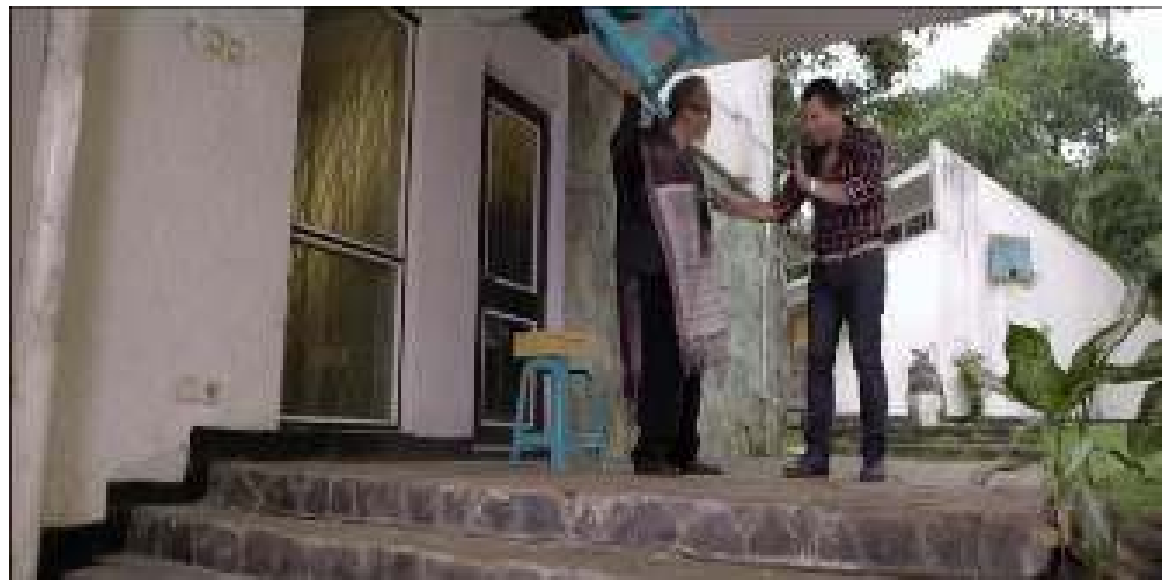

Gambar. 3 Kakek Tiar Memakai Ulos

(Sumber: Capture film Lamaran, 2020)

Setiap pigura akan diberi beraneka ragam lukisan, seperti antiganting sigumang, batuhi ansimun, dan sebagainya. Warna, lukisan, serta corak (ragi) memberi kesan seolaholah ulos benar-benar hidup. Oleh karena itu, orang menyebut ulos tersebut dengan ragi idup yang melambangkan kehidupan. Selain lambang kehidupan, ulos ini juga dilambangkan dengan doa restu untuk kebahagian dalam kehidupan, terutama dalam hal keturunan, agar banyak anak (gabe) bagi setiap keluarga dan panjang umur (saur sarimatua). Hal ini selaras dengan tujuan orang Batak Toba hidup di dunia memiliki harta, keturunan, dan jabatan, yang lazim disebut dengan tiga ha yaitu, hagabeon (keturunan), hasangapon (harta), dan hamoraon (strata sosial).

Pengambilan gambar pada adegan tersebut menggunakan teknik long shot yaitu jenis pengambilan gambar yang difokuskan keseluruh tubuh manusia. Teknik long shot yaitu jenis pengambilan gambar untuk pengambilan seluruh tubuh fisik manusia agar tampak jelas, namun latar belakang masih dominan. Long shot sering kali digunakan sebagai establishing shot, yakni shot pembuka sebelum digunakan shot-shot yang berjarak lebih dekat (Pratista, 2017). Komposisi gambar yang digunakan pada gambar diatas juga menggunakan komposisi gambar dinamis. Komposisi gambar dinamis mampu menciptakan kesan yang mengandung resiko dan bergerak. Hal ini terlihat dari seorang kakek yang mengangkat kursi berwarna hijau dan seorang lelaki yang sedang mengangkat kedua tangannya. Adapun pencahayaan tersebut menggunakan cahaya alami yang berasal dari matahari, namun adegan yang terdapat pada gambar tersebut terlihat sedikit redup serta lebih kontras dengan kostum berwarna cokelat dan senada dengan dinding dan pintu yang terlihat pada gambar.

Selajuntnya, adegan yang terlihat pada gambar dibawah ini terlihat ayah Tiar juga menggunakan kostum ulos. ulos tersebut bernama ulos ragihotang, ulos ini mempunyai keistimewaan yang dapat dilihat dari fungsi sosialnya. Pada adegan yang terlihat pada gambar dibawah ini menunjukan orang tua Tiar yang sedang melihat sebuah foto yang berada dihadapan mereka. Foto yang mempunyai latar belakang berwarna putih, senada dengan kain penutup jendela yang berwarna putih, pencahayaan yang terdapat pada ruangan tersebut dihasilkan oleh lampu yang terlihat dibelakang lelaki yang memasukkan tangan kedalam kantong celana. 


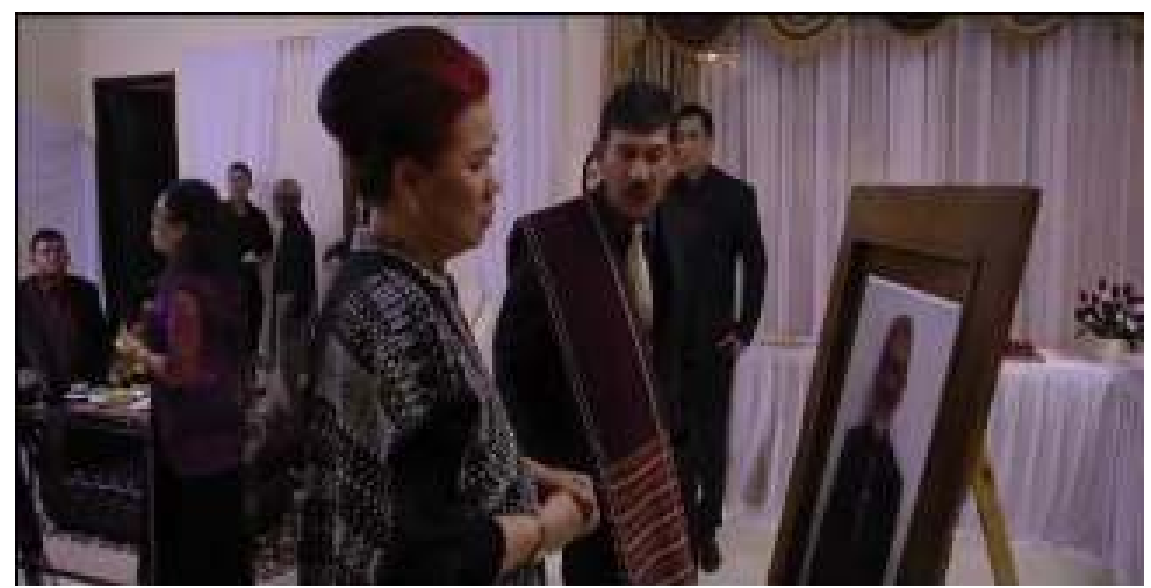

Gambar. 4 Kedua Orang Tua Tiar Memakai Ulos

(Sumber: Capture film Lamaran, 2020)

Ulos ini digunakan untuk mengulosi seseorang dengan harapan agar Tuhan akan memberikannya hasil yang baik, dan orang yang rajin berkerja. Dalam upacara kematian, ulos ini dipakai untuk membungkus mayat. Sedangkan untuk upacara penguburan kedua kalinya yang disebut dengan mengongkal holi, digunakan juga untuk membungkus tulangbelulangnya. Sementara menurut Austin Alexander Parhusip, jenis ulos yang dipakai tergantung pada status sesorang di dalam kekerabatan adat Batak, sementara yang dipakai oleh seorang bapak yang terlihat pada adegan yang terdapat pada gambar tersebut merupakan jenis ulos ragihotang, digunakan sebelum mempunyai cucu (wawancara, 04 Desember 2019). Sementara teknik yang digunakan dalam pengambilan gambar tersebut menggunakan teknik medium shot dimana dalam pengambilan gambar melalui pinggang hingga kepala, sehingga objek yang terlihat lebih fokus, sedangkan komposisi gambar yang terdapat pada gambar tersebut yaitu komposisi statis. Komposisi Statis atau yang biasa disebut dengan Dead Center ialah komposisi yang meletakkan subyek di tengah bidang, dimana subyek tersebut adalah seorang ibu dan bapak penggunaan komposisi statis tersebut terlihat pas sehingga menciptakan kesan sedih. Kesan sedih tersebut dimunculkan karena orang tua mereka meninggal dunia.

Adegan selanjutnya juga terlihat Tiar dan Raymond juga memakai kain ulos. Seperti terlihat pada gambar dibawah ini.

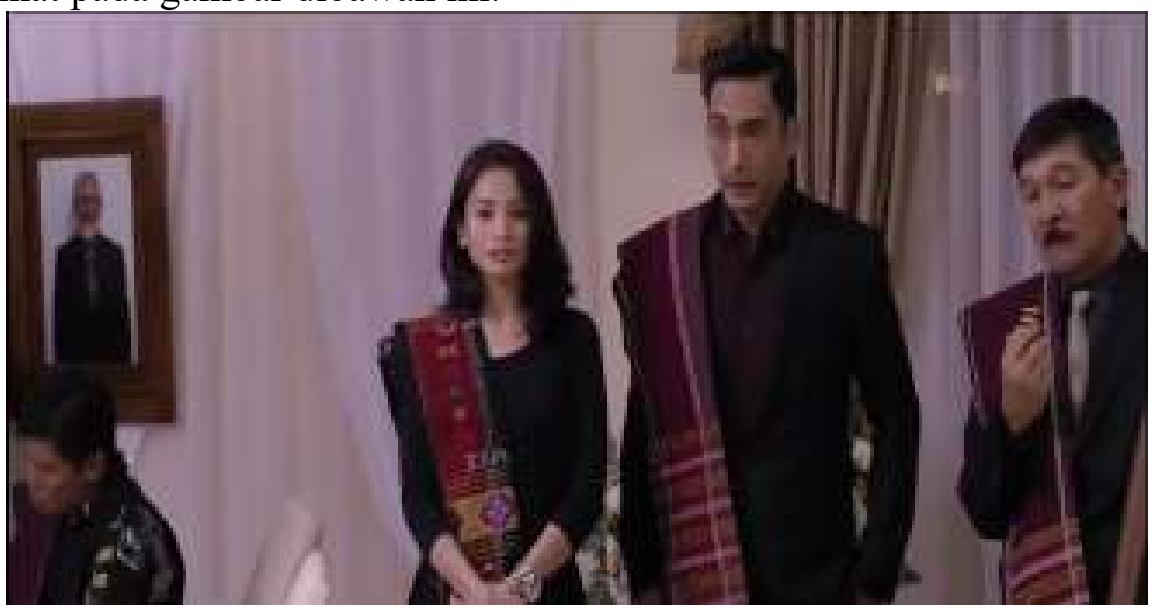

Gambar. 5 Tiar dan Raymond Memakai Ulos (Sumber: Capture film Lamaran, 2020) 
Pada adegan yang terlihat pada gambar diatas, terlihat tiga orang yang sedang berada didalam ruangan duka. Raymond dan ayah Tiar menggunakan ulos yang sama yaitu ulos ragihotang, sementara Tiar menggunakan ulos yang dengan motif yang beda. Ulos yang digunakan Tiar dikenal dengan nama ulos sadum. Ulos ini biasanya diberikan kepada anak kesayangan dalam sebuah keluarga. Tujuan pemberian ulos ini agar suatu saat nanti anak yang disayangi dapat membawa hal-hal kebajikan yang banyak dan besar. Selain itu, si anak akan dapat mencapai apa yang dicita-citakannya dan mendapat berkat yang banyak dan besar pula dari Tuhan. Teknik pengambilan gambar yang terdapat pada adegan diatas menggunakan teknik medium shot. Teknik medium shot yaitu teknik yang digunakan untuk pengambilan gambar yang dilakukan dari batas pinggang hingga keatas kepala. Sosok manusia mendominasi frame dan latar belakang tidak menjadi dominan. Pencahayaan yang terdapat dalam scene tersbut adalah frontal lighting, yaitu cahaya cenderung menghapus bayangan dan menegaskan objek atau wajah karakter sedangkan sudut pengambilan menggunakan teknik eye level angle.

Adegan selanjutnya, yang mencerminkan identitas budaya Batak Toba terlihat saat proses pernikahan Aan dan Tiar. Pada adegan pernikahan Aan dan Tiar terlihat ekpresi gembira yang terlihat dari visual pada pengantin pria dan pengantin wanita. Selain itu, juga terlihat dan seorang ibu menggunakan kebaya, sehingga yang membedakan pengantin dengan yg lainya adalah tali-tali atau ikat kepala yg menggunakan ulos. Tali-tali atau ikat kepala menggunakan ulos mangiring. Ikat kepala dipakai sebagai pengganti topi. Tata Rias yang digunakan oleh kedua pengantin juga terlihat lebih natural dan tidak mencolok. Tata rias dibuat menyesuaikan suasana dan dan corak kostum yang digunakan oleh kedua mempelai. Paduan kostum dan tata rias mampu memunculkan suasan dan kesan gembira. Pengambilan gambar yang terdapat pada adegan tersebut menggunakan teknik knee shot yaitu teknik yang digunakan untuk mengambil gambar dari batas lutut hingga ke kepala. Sementara sudut pengambilan gambar menggunakan teknik high angle. Adapun adegan tersebut terlihat pada gambar dibawah ini.

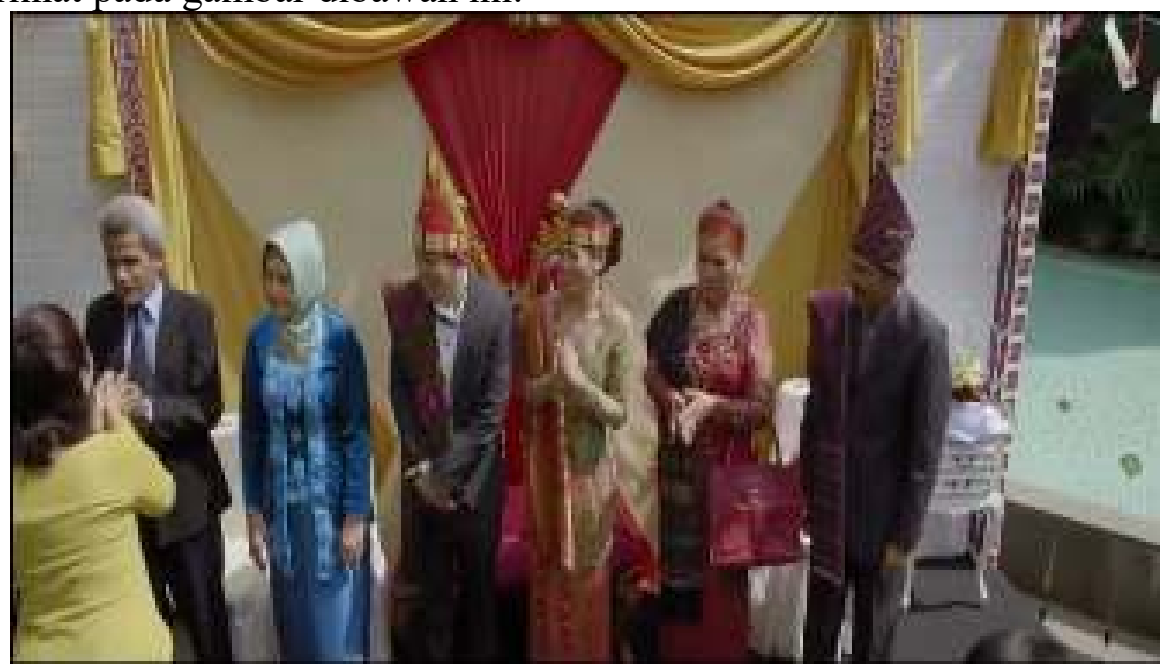

Gambar. 6 Prosesi Pernikahan Aan dan Tiar (Sumber: Capture film Lamaran, 2020)

\section{Pemain dan Pergerakan}

Para aktor yang bermain pada film Lamaran merupakan para aktor yang sudah banyak membintangi berbagai jenis judul film. Aktor yang dipilih oleh Monty Tiwa selaku sutradara sudah memiliki banyak pengalaman dalam dunia akting film. Acha Septriasa yang memerankan peran sebagai Tiar. Reza Nangin yang memerankan peran sebagai Aan. Acha Septriasa dan Reza Nangin memerankan tokoh utama protagonis dalam film Lamaran. Selain itu, Arie Untung yang memerankan peran sebagai La Abo, Sascha 
Stevenson yang memerankan peran sebagai Sasha. Arie Untung dan Sascha Stevenson dalam film Lamaran memerankan tokoh deatragonis yang membantu Aan dan Tiar dalam mencapai misi. Yang memerankan tokoh antagonis dalam film Lamaran diperankan oleh Dwi Sasono yang berperan sebagai Arif Rupawan dan Mongol Stres yang memerankan peran sebagai Dono ajudan Dwi Sasono dalam menghalangi Tiar untuk mengukap kasus korupsi yang menimpa Basuki yang diperankan oleh Marwoto. Selain itu, masih ada beberapa tokoh yang memerankan karakter pada film Lamaran.

Akting pemain dalam film Lamaran merupakan bentuk akting yang realistis yang mampu mencerminkan kehidupan sehari-hari. Pada scene 5 yang terdapat pada film Lamaran bercerita mengenai Tiar yang ditegur oleh pamannya Rico yang diperankan oleh Tora Sudiro. Rico menegur Tiar karena kecerobosannya menghalagi Dono Ketika melepas tembakan kearah Basuki.

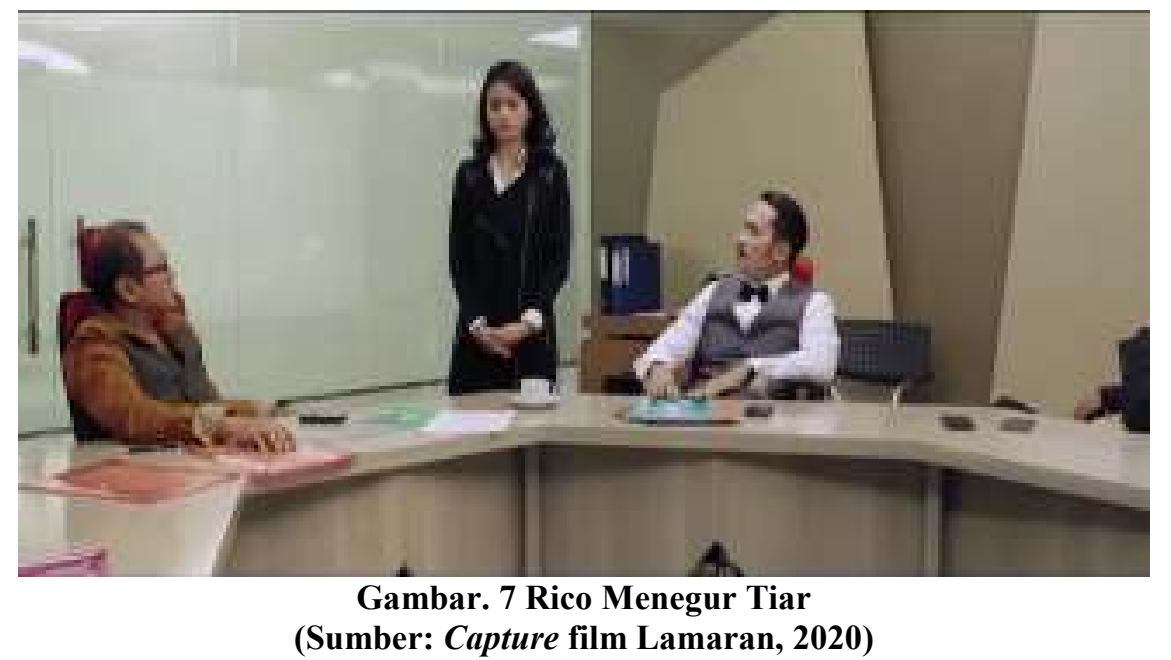

Identitas budaya Batak Toba yang tercermin dalam scene diatas adalah sistem kekerabatan yang ada dalam struktur keluarga etnis Batak Toba. Tiar bekerja dikantor tulangya sebagai pengacara dan diberikan tugas untuk menyelesaikan kasus korupsi yang menimpa Basuki. Tulang dalam sistem kekerabatan Batak Toba merupakan saudara laki-laki ibu. Pada scene tersebut tercermin bahwa hubungan kekerabatan antara Tiar dan tulangnya Rico masih terjalin dengan harmonis dengan bekerjanya Tiar di Kantor Rico. Sistem kekerabatan mempunyai arti penting dalam banyak masyarakat baik masyarakat sederhana maupun masyarakat yang sudah maju, hubungan dengan nenek moyang dan kerabat adalah kunci hubungan dalam struktur sosial (Harahap, 2016).

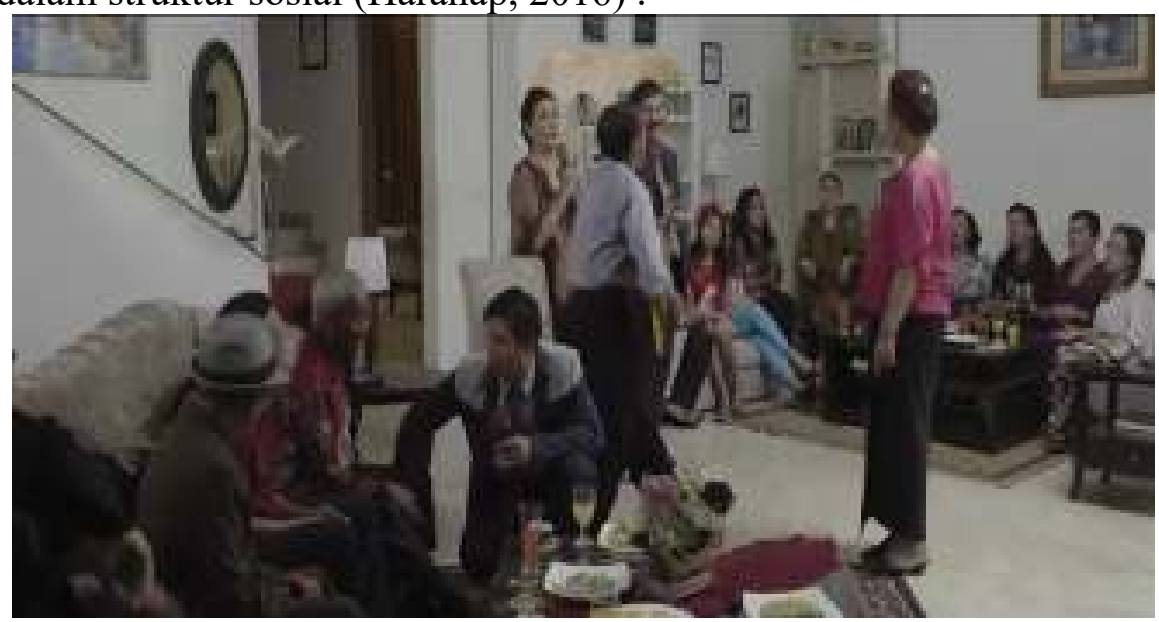

Gambar. 8 Acara Keberhasilan Tiar

(Sumber: Capture film Lamaran, 2020) 
Scene 15 yang terdapat pada adegan gambar diatas menceritakan keluarga Tiar sedang merayakan keberhasilan Tiar menjadi seorang pengacara. Keluarga Tiar sangat bangga dengan keberanian dan keberhasilan Tiar memegang kasus besar yang melanda Basuki. Pergerakan pemain pada scene 15 terlihat sangat bahagia dan saling berinteraksi satu dengan lainnya dengan iringan lagu. Identitas budaya Batak Toba pada scene 15 tercermin dari tindakan individu dan kelompok yang mengadakan perkumpulan dirumah orang tua Tiar. Kedua orang tua Tiar mengundang sanak saudara yang masih memiliki hubungan kekerabatan untuk hadir dan merayakan keberhasian Tiar. Kebiasaan orang Batak Toba ketika merayakan keberhasilan senantiasa diiringi dengan nyanyian dan musik. Akan tetapi, pada scene 15 tersebut alat musik yang divisualkan hanya gitar.

Pergerakan pemain yang terlihat pada scene diatas menceritakan tentang Aan tibatiba datang ke acara perayaan keberhasilan Tiar dirumahnya. Tiar sangat terkejut dengan kedatang Aan yang ditemani oleh La Abo dan Sasha. Ketika melihat kedatangan Aan sepontan keluarga Tiar terkejut dengan pengakuan Tiar kalau Aan adalah pacarnya dan calon suaminya. Sontak keluarga Tiar menayakan kalau Aan bermarga apa. Mendengar pertanyaan tentang marga sontak membuat Aan terkejut. Seperti terlihat pada gambar dibawah ini.

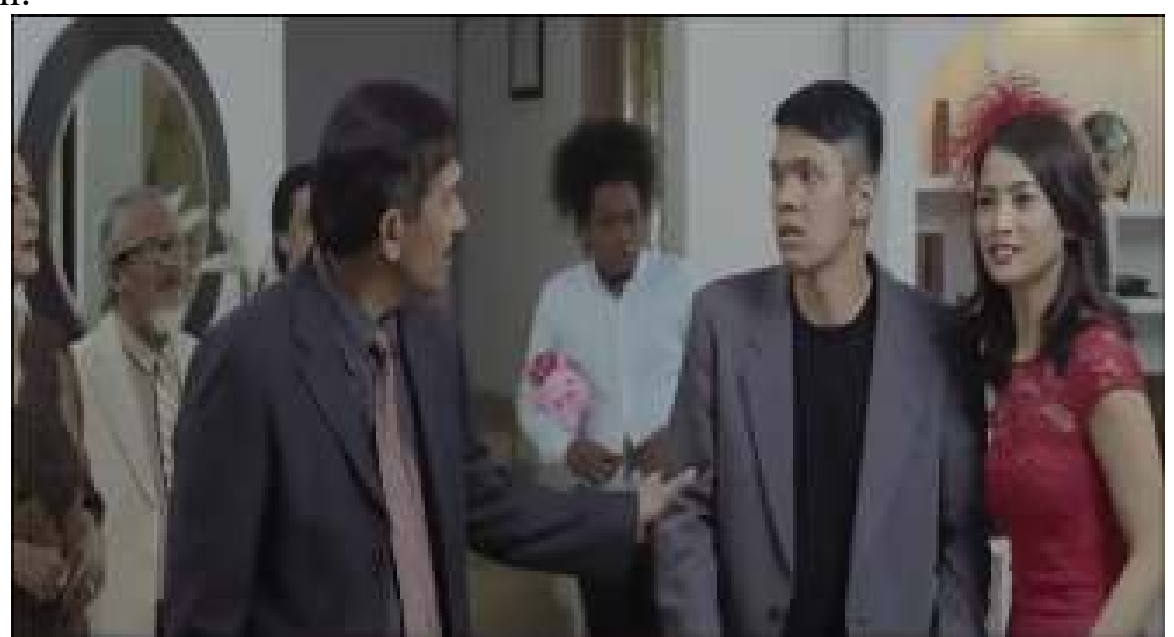

Gambar. 9 Ayah Tiar Menanyakan Marga Aan

(Sumber: Capture film Lamaran, 2020)

Ekpresi terkejut terlihat dari mimik wajah Aan ketika menatap wajah Ayah Tiar yang diambil dengan teknik medium shot. Ketika keluarga Tiar mengetahui kalau Aan bukan berdarah Batak dan tidak memiliki marga. Membuat La Abo dan Sasha mengatur stategi agar Aan bisa memiliki marga dan menikahi Tiar. Marga merupakan identitas dan jadi diri sebagai penanda bagi orang Batak. Adanya marga hubungan sistem kekerabatan akan tersambung dalam tarombo (silsila keluarga). Marga adalah nama persekutuan sekelompok masyarakat yang merupakan keturunan dari seorang kakek menurut garis keturunan bapak, yang pada umumnya memiliki tanah bersama di tanah leluhur.Bahasa dan aksara juga merupakan identitas suku bangsa batak (Sipahutar, 2017).

Untuk mendapatkan marga La Abo, Sasha, dan Aan mendatangi Meja yang diperankan oleh Ozzol Ramdan. La Abo membuat kesepakatan dengan Meja agar Aan bisa memiliki marga. Meja mengatakan bahwa untuk mendapatkan marga tidak mudah dan harus melakukan prosesi adat. Dalam pelaksanaan proses adat ada beberapa persyaratan yang harus dipenuhi oleh Aan termasuk menyembelih hewan seperti babi atau sejenis. Dalam kehidupan suku Batak Toba terdapat empat hewan peliharaan yang sangat berharga karena biasa digunakan sebagai hewan konsumsi dalam pesta adat, yaitu: Babi, lombu 
(Lembu), hoda (kuda), horbo (kerbau). Kuda biasa disebut hoda debata yang berarti kuda untuk dipersembahkan khusus kepada Tuhan (Debata). Adapun horbo dan lombu merupakan hewan yang dipersembahkan juga disajikan kepada debata namun bedanya kalau hoda tidak fokus untuk disajikan (Marbun \& Hutapea, 1987). Kerbau biasa disembelih untuk dipersembahkan pada acara ritual khusus, sebab itu ada istilah horbo debata. Kerbau melambangkan keperkasaan dengan dua tanduknya. Kerbau juga termasuk hewan yang disayang karena banyak membantu pekerjaan manusia di sawah. Sementara itu, menurut Pinondang Hutapea, bahwa dalam setiap upacara adat dalam masyarakat Batak seperti Batak Toba babi merupakan sajian umum. Jika ada tamu terhormat yang dating berkunjung, sudah selayaknya tuan rumah menyembelih Babi sebagai hidangan untuk disantap Bersama tamu tersebut. Selain itu, babi mempunyai tempat yang sangat luas yang meliputi segala macam perjamuan, baik dalam jamuan duka cita maupun jamuan Bahagia seperti pernikahan (wawancara, 02 Januari 2020).

Senada dengan pernyataan tersebut, Austin Alexander Parhusip juga menambahkan kalau binatang sembelihan, jaman dulu binatang sembelihan tidak memakai binatang Babi (B2), karena agama kuno Batak Toba "Agama Parmalim" melarang makan Babi, sehingga permulaan Babi sebagai binatang sembelihan dimulai pada masa colonial Belanda. Pada waktu itu, Belanda memusnahkan ternak kambing, kerbau lembu dan lain-lain. Kepercayaan ini tetap mewarisi adat budaya Batak leluhur tetap eksis yg pusatnya di Hutaginjang. Kalau binatang sembelihan pada acara adat Batak disebut hambar juhut dan dekke.

Adapun bentuk parjambaran dalam pesta adalah sebagai berikut:

Tabel 1. bentuk parjambaran dalam pesta

\begin{tabular}{|c|c|}
\hline $\begin{array}{c}\text { Juhut kepada } \\
\text { Parboru }\end{array}$ & $\begin{array}{c}\text { Dekke kepada } \\
\text { Paranak }\end{array}$ \\
\hline Kerbau & Lembu \\
\hline Lembu & Babi \\
\hline Babi & Ayam \\
\hline Ayam & Ihan (dekke) \\
\hline
\end{tabular}

Arti juhut dan dekke dapat diperhatikan pada tabel diatas, dekke kepada paboru adalah lembu, babi dan seterusnya, pengertian dekke disini bukan seperti ikan-lauk-lompan. Paranak menyerahkan tudu-tudu ni sipanganon "panjuhuti, parboru menyerahkan dekke dengan mengatakan "on ma dekke sahat, asa sahat nauli na denggan di hamu” pada waktu marpudun saut dibicarakan tentang apa yang disiapkan paranak untuk panjuhuti dan bagaimana kesediaan parboru untuk menyediakan dekke. Apabila parboru hanya kan menyerahkan "dekke simudur-udur", maka sebaiknya paranak menyesuaikan diri atas panjuhuti, yaitu hanya "baik" dengan lombu sitio-tio, yaitu lombu natinutungan, yang statsunya sudah setara dengan pinahan lobu, karena tudu-tudu ni sipanganan sudah dipotong menurut bagian-bagian sebagaimana pada pinahan lobu (JP. Sitanggang, 2014).

Pada scene tersebut terlihat Kijang dan dua temannya sedang menghadiri acara pesta dan mereka juga menyumbang atau didalam bahasa Batak dinamakan tumpak. Tumpak sendiri mempunyai arti sumbangan atau bantuan, biasanya dalam acara pesta dimasukan dalam amplop, selain menyumbang Kijang dan kedua temannya juga memakan sebuah makanan yang dinamakan dengan arsik. Austin Alexander Parhusip juga mengatakan bahwa didalam bahasa Batak arti dari arsik itu sendiri sebenarnya mengeringkan, tetapi jika didalam masakan, arsik mempunyai arti masakan khas Batak, biasanya ikan mas dibuat sesuai dngan bumbu arsiknya, biasanya disajikan dalam bentuk makanan agar mendoakan kepada seseorang yg diberikan. Ikan mas arsik diberikan 
biasanya pada acara pesta, acara 7 bulanan saat wanita berbadan dua, acara pemberkatan lainya, biasanya diberikan dengan kalimat dalam bentuk doa atau berkat kepada seseorang. Senada dengan pernyataan tersebut Pinondang Hutapea juga menyatakan bahwa ikan mas bagi orang Batak sebagai ikan untuk melakukan upah-upah (wawancara, 02 Januari 2020).

Teknik pengambilan gambar yang digunakan pada scene tersebut sama dengan scene sebelumnya yaitu menggunakan teknik medium shot dan komposisi gambar yang dinamis, dimana komposisi ini sangat efektif dalam menciptkan kesan yang bergerak, riang dan tertawa serta mengandung resiko, dimana komposisi tersebut terlihat dari ekspresi Kijang dan temannya yang terlihat senang namun mengandung resiko yang dapat terlihat dari ekspresi Kijang yang tersenyum namun tidak lepas dan kedua bolah mata yang terlihat kekiri, serta satu temannya yang sedang terlihat kebingungan. Pencahayaan yang terdapat dalam scene tersebut cenderung lebih redup, namun terlihat kontras terhadap kostum yang digunakan oleh pemain, sehingga subjek terlihat dengan jelas dan menghasilkan efek visualisasi yang indah.

\section{KESIMPULAN}

Adapun kesimpulan dari penelitian ini menunjukkan bahwa identitas budaya batak Toba pada film Lamaran yang tercermin dalam struktur mise en scene yang terdiri dari aspek setting, kostum dan tata rias, dan pemain dan pergerakan. Aspek setting pada film Lamaran secara keseluruhan mengambil lokasi syuting di daerah Jakarta. Akan tetapi, ada beberapa setting yang mencerminkan identitas budaya Batak Toba. Setting tersebut dijadikan sebagai properti pelengkap agar tema budaya Batak pada Film Lamaran dapat dirasakan, diamati dalam konteks visual film. Setting yang mencerminkan identitas budaya Batak Toba terlihat desain panggung terbuat dari motif gorga. Adanya pemanfaat setting dengan motif gorga tentu sutradara ingin memberikan informasi terkait konteks sosial budaya yang dimiliki oleh Batak Toba.

Identitas budaya Batak Toba juga tercermin dari kostum dan tata rias yang digunakan oleh aktor maupun aktris pada film Lamaran. Kostum yang mencerminkan identitas budaya Batak Toba dominan terlihat pada pemakain ulos oleh para aktor dan aktris pada film Lamaran. Selain itu, tokoh utama juga memakai pakaian pengantin yang menandakan kostum identitas budaya Batak Toba. Tata rias pada film Lamaran dibuat dengan natural sehingga memunculkan kesan alami dan tidak menjolok. Selain itu, tata rias juga disesuaikan dengan kostum yang dipakai oleh para aktor dan aktris pada film Lamaran. Untuk melihat identitas budaya Batak pada film Lamaran juga dapat dilihat dari pemain dan pergerakan. Pada film Lamaran para pemain dibagi ke dalam tiga kategori yaitu, protagonis, antagonis, dan deatragonis. Protagonis dalam film Lamaran diperankan oleh Aan dan Tiar. Tokoh antagonis diperankan oleh Arif Rupawan dan Dono. Adapun yang berperan sebagai deatagonis adalah La Abo dan Sasha. Identitas budaya Batak Toba yang tercermin dalam pemain dan pergerakan adalah sistem kekerabatan yang terlihat dari Tindakan yang dilakukan oleh para aktor. Selain itu, pentingnya marga Ketika ingin menikahi seorang perempuan berdarah Batak Toba.

\section{UCAPAN TERIMA KASIH}

Peneliti mengucapkan terima kasih kepada Direktorat Riset dan Pengabdian Masyarakat Direktorat Jenderal Penguatan Riset dan Pengembangan Kementerian Riset, Teknologi dan Pendidikan Tinggi Republik Indonesia (KEMENRISTEKDIKTI) yang telah mendanai penelitian ini. 
Peneliti juga mengucapkan terima kasih kepada LLDIKTI wilayah I Sumatera Utara, LPPM Universitas Potensi Utama Medan, dan informan dalam penelitian ini.

\section{DAFTAR PUSAKA}

\section{BUKU}

[1] Amura. (1989). Perfilman di Indonesia. Jakarta: LKMII.

[2] Hutapea, I.M.T \& Marbun, M.A. (1987). Kamus Budaya Batak Toba. Jakarta: Balas Pustaka.

[3] J.P. Sitanggang. (2014). Manajemen Keuangan Perusahaan. Jakarta: Mitra Wacana Media.

[4] McDonald, T. J. (2010). Exploring Costume and Transformation. London New York: I.B Tauris.

[5] Pratista, Himawan. (2008). Memahami Film, Yogyakarta: Montase Press.

[6] Pratista, Himawan. (2017). Memahami Film Edisi 2, Yogyakarta: Homerian Pustaka.

[7] Santosa. (2012). Komunikasi Seni (Aplikasi dalam Pertunjukan Gamelan). Surakarta: Isi Press Surakarta.

\section{JURNAL}

[8] Andriyanti, S. (2008). Kontinuitas Gorga Batak Toba. Pantun Jurnal Ilmiah Seni Budaya, 1(19), 132-144.

[9] Arsi, M., \& Sobur, A. (2019). Makna Identitas Budaya Dan Konflik Antaretnis Dalam Film “ Crazy Rich Asians .” 12(1), 46-60.

[10] Harahap, D. (2016). Implikasi Sistem Kekerabatan Dalihan Na Tolu (Studi Pada Keluarga Urban Muslim Batak Angkola Di Yogyakarta). Riset, Xii(1), 121-134.

[11] Santosa, B. (2006). Bahasa Dan Identitas Budaya. Sabda, 1(September).

[12] Sipahutar, A. (2017). Nilai Budaya Keluarga Batak Toba Di Kelurahan Sail Tenayan Raya. Jom Fisip, 4(2), 1-14.

[13] Sugihartoni, R. A., \& Sintowoko, D. A. W. (2014). Kostum Dalam Membangun Karakter Tokoh Pada Film Soekarno. Capture, 6(May).

[14] Saragi, Daulat. (2008). Filosofi Gorga, Makna Komunikasi Visual Yang Dicetak Dalam Hati Hingga Dicetak Dengan Teknik Digital. Seni Rupa Fbs Unimed, 5(2).

[15] Thalib, A. A. (2017). Isu-Isu Identitas Budaya Nasional Dalam Film “ Tenggelamnya Kapal Van Der Wijck ." Satwika, 1(2). 